\title{
Source apportionment and sensitivity analysis: two methodologies with two different purposes
}

\author{
Alain Clappier ${ }^{1}$, Claudio A. Belis ${ }^{2}$, Denise Pernigotti ${ }^{2}$, and Philippe Thunis ${ }^{2}$ \\ ${ }^{1}$ Université de Strasbourg, Laboratoire Image Ville Environnement, Strasbourg, France \\ ${ }^{2}$ European Commission, Joint Research Centre, Ispra, Italy \\ Correspondence to: Philippe Thunis (philippe.thunis@ec.europa.eu)
}

Received: 4 July 2017 - Discussion started: 12 July 2017

Revised: 3 October 2017 - Accepted: 6 October 2017 - Published: 24 November 2017

\begin{abstract}
This work reviews the existing methodologies for source apportionment and sensitivity analysis to identify key differences and stress their implicit limitations. The emphasis is laid on the differences between source "impacts" (sensitivity analysis) and "contributions" (source apportionment) obtained by using four different methodologies: brute-force top-down, brute-force bottom-up, tagged species and decoupled direct method (DDM). A simple theoretical example to compare these approaches is used highlighting differences and potential implications for policy. When the relationships between concentration and emissions are linear, impacts and contributions are equivalent concepts. In this case, source apportionment and sensitivity analysis may be used indifferently for both air quality planning purposes and quantifying source contributions.

However, this study demonstrates that when the relationship between emissions and concentrations is nonlinear, sensitivity approaches are not suitable to retrieve source contributions and source apportionment methods are not appropriate to evaluate the impact of abatement strategies. A quantification of the potential nonlinearities should therefore be the first step prior to source apportionment or planning applications, to prevent any limitations in their use. When nonlinearity is mild, these limitations may, however, be acceptable in the context of the other uncertainties inherent to complex models.

Moreover, when using sensitivity analysis for planning, it is important to note that, under nonlinear circumstances, the calculated impacts will only provide information for the exact conditions (e.g. emission reduction share) that are simulated.
\end{abstract}

\section{Introduction}

When pollutant concentrations exceed the thresholds set in the legislation, competent authorities must take actions to abate pollution. Those abatement strategies consist in reducing the precursor's emission of the different activity sector to reduce pollutant concentrations but they are challenging to design because of the complex relationships that link emissions and pollutants. Indeed, the concentration of a pollutant at a given location generally results from direct emissions and from interactions in the atmosphere among different emission precursors, emitted by a variety of sources. For example, particulate matter (denoted here as PM) results from the interaction and combination of five different precursors (PPM, $\mathrm{NO}_{x}, \mathrm{SO}_{2}, \mathrm{NH}_{3}$ and VOC), which can be emitted by different activity macro-sectors (e.g. residential, transport, industrial and agriculture; Seinfeld and Pandis, 2016).

Two different approaches are currently used to support air quality decision makers: source apportionment and sensitivity analysis.

- Source apportionment quantifies the contribution of an emission source (or precursor) to the concentration of one pollutant at one given location.

- Sensitivity analysis estimates the impact on pollutant concentration that results from a change of one or more emission sources.

In practice, source apportionment is often used for planning purposes. It is indeed intuitive to use source apportionment to detect the activity sectors that need to be tackled in priority in an air quality plan. On the other hand, sensitivity analysis is often used as an approach to derive source contributions, 
e.g. SHERPA (Thunis et al., 2016), FASST (Crippa et al., 2017) and GAINS (Kiesewetter et al., 2015).

The main objective of this work is to review the existing methodologies, identify key differences and stress their implicit limitations. We particularly focus on the differences between concentration "impacts" (sensitivity) and "contributions" (source apportionment) obtained with different methodologies. We make use of a simple theoretical example to compare the approaches, highlight differences and potential implications in terms of policy. In the following sections, we analyse first how these methodologies work in a simple linear case before generalising it to more complex nonlinear situations.

\section{Linear simplification and implications}

Let us consider $C$ a pollutant concentration at one location that is a function of three variables $\left(E_{1}, E_{2}\right.$ and $\left.E_{3}\right)$, i.e. the emissions of three precursors or sources within a given domain: $C=C\left(E_{1}, E_{2}, E_{3}\right)$. For a linear relationship between the function $C$ and the three variables $E_{1}, E_{2}$ and $E_{3}$, we can write

$C\left(E_{1}, E_{2}, E_{3}\right)=C(0,0,0)+P_{1} E_{1}+P_{2} E_{2}+P_{3} E_{3}$,

where $P_{1}, P_{2}$ and $P_{3}$ are three constant coefficients.

On the other hand, the sensitivity of the concentration to a change of a given emission source can be quantified via partial derivatives. For Eq. (1) this gives

$\frac{\partial C}{\partial E_{1}}=P_{1} ; \frac{\partial C}{\partial E_{2}}=P_{2} ; \frac{\partial C}{\partial E_{3}}=P_{3}$.

In Clappier et al. (2017) the coefficients $\left(P_{1}, P_{2}\right.$ and $\left.P_{3}\right)$ are referred to as "potencies" - the authors used this concept to analyse the model response to emission changes in different European countries.

The consequences of a linear relationship between concentration and emission sources are twofold:

1. All higher-order derivatives (order 2 and beyond) are null, including those involving two or more emission sources (crossed derivatives), as the impact of a change in one emission source is independent from all others.

2. The first-order partial derivatives are constant and can therefore be calculated with finite differencing, between any couple of emission levels, for example a base case (denoted BC) and a background (denoted as 0).

The potency equations then read as

$P_{1}=\frac{\Delta C_{0}^{\mathrm{BC} C_{1}}}{E_{1}^{\mathrm{BC}}} ; P_{2}=\frac{\Delta C_{0}^{\mathrm{BC}}}{E_{2}^{\mathrm{BC}}} ; P_{3}=\frac{\Delta C_{0}^{\mathrm{BC}}}{E_{3}^{\mathrm{BC}}}$ with

$\Delta C_{0}^{\mathrm{BC}_{1}}=C\left(E_{1}^{\mathrm{BC}}, 0,0\right)-C(0,0,0)$,

$\Delta C_{0}^{\mathrm{BC}_{2}}=C\left(0, E_{2}^{\mathrm{BC}}, 0\right)-C(0,0,0)$,

$\Delta C_{0}^{\mathrm{BC}}=C\left(0,0, E_{3}^{\mathrm{BC}}\right)-C(0,0,0)$.

Together with "potencies", Clappier et al. (2017) also introduce the concept of "potential", defined as the concentration change resulting from a total reduction of the emissions (from BC to 0). The "potential" can be calculated via relation (1) applied between the BC and background levels as

$\Delta C_{0}^{\mathrm{BC}}=\Delta C_{0}^{\mathrm{BC}_{1}}+\Delta C_{0}^{\mathrm{BC}_{2}}+\Delta C_{0}^{\mathrm{BC}_{3}}$,

where $\Delta C_{0}^{\mathrm{BC}}=C\left(E_{1}^{\mathrm{BC}}, E_{2}^{B C}, E_{3}^{\mathrm{BC}}\right)-C(0,0,0)$.

Equation (2) can directly be used for source apportionment purpose, with $\Delta C_{0}^{\mathrm{BC}_{1}}$ the concentration change resulting from a total reduction of the emission source (or precursor) $E_{1}$, reflecting the contribution of $E_{1}$ to the $\mathrm{BC}$ concentration. Similarly, $\Delta C_{0}^{\mathrm{BC}_{2}}$ and $\Delta C_{0}^{\mathrm{BC}_{3}}$ are the contributions of $E_{2}$ and $E_{3}$. Equation (2) shows that, in the linear case, the concentration change resulting from a simultaneous reduction of all emission sources $\left(\Delta C_{0}^{\mathrm{BC}}\right)$ is equal to the sum of the emission source contributions.

In the next sections, we will explore how this simple conclusion changes when nonlinear relationships are considered. In particular, we will assess which implications (and limitations) these nonlinearities have in terms of source apportionment and sensitivity analysis.

\section{Brute-force method}

The "brute-force" method consists in estimating the concentration change by performing and subtracting two simulations, one with and the second without a specific emission source to be analysed (Blanchard, 1999; Yarwood et al., 2004).

In nonlinear situations, the concentration change resulting from a set of emission sources is no longer equivalent to the sum of the concentration changes resulting from emission sources changed individually. In the following, we refer to the work of Stein and Alpert (1993) who proposed an approach to decompose an overall impact into single (one emission source only) and combined (multiple emission sources) impacts.

\subsection{Bottom-up formulation}

We consider here three precursor's emissions $E_{1}, E_{2}$ and $E_{3}$, which are changing from a low (denoted as "L") to a high level (denoted as "H"). In a bottom-up approach, the low emission level is chosen as the reference. With these definitions and notation, the impact on concentration resulting 
from a change of one only of the three precursor's emissions can be written as follows:

$$
\begin{aligned}
& \Delta C_{\overline{\mathrm{L}}}^{\mathrm{H}_{1}}=C\left(E_{1}^{\mathrm{H}}, E_{2}^{\mathrm{L}}, E_{3}^{\mathrm{L}}\right)-C\left(E_{1}^{\mathrm{L}}, E_{2}^{\mathrm{L}}, E_{3}^{\mathrm{L}}\right) \\
& \Delta C_{\overline{\mathrm{L}}}^{\mathrm{H}_{2}}=C\left(E_{1}^{\mathrm{L}}, E_{2}^{\mathrm{H}}, E_{3}^{\mathrm{L}}\right)-C\left(E_{1}^{\mathrm{L}}, E_{2}^{\mathrm{L}}, E_{3}^{\mathrm{L}}\right) \\
& \Delta C_{\overline{\mathrm{L}}}^{\mathrm{H}_{3}}=C\left(E_{1}^{\mathrm{L}}, E_{2}^{\mathrm{L}}, E_{3}^{\mathrm{H}}\right)-C\left(E_{1}^{\mathrm{L}}, E_{2}^{\mathrm{L}}, E_{3}^{\mathrm{L}}\right),
\end{aligned}
$$

while the impact on concentration resulting from the simultaneous changes of two or three precursor's emissions would be written as

$$
\begin{gathered}
\Delta C_{\overline{\mathrm{L}}}^{\mathrm{H}_{1}, \mathrm{H}_{2}}=C\left(E_{1}^{\mathrm{H}}, E_{2}^{\mathrm{H}}, E_{3}^{\mathrm{L}}\right)-C\left(E_{1}^{\mathrm{L}}, E_{2}^{\mathrm{L}}, E_{3}^{\mathrm{L}}\right) \\
\Delta C_{\overline{\mathrm{L}}}^{\mathrm{H}_{1}, \mathrm{H}_{3}}=C\left(E_{1}^{\mathrm{H}}, E_{2}^{\mathrm{L}}, E_{3}^{\mathrm{H}}\right)-C\left(E_{1}^{l}, E_{2}^{\mathrm{L}}, E_{3}^{\mathrm{L}}\right) \\
\Delta C_{\overline{\mathrm{L}}}^{\mathrm{H}_{2}, \mathrm{H}_{3}}=C\left(E_{1}^{\mathrm{L}}, E_{2}^{\mathrm{H}}, E_{3}^{\mathrm{H}}\right)-C\left(E_{1}^{L}, E_{2}^{\mathrm{L}}, E_{3}^{\mathrm{L}}\right) \\
\Delta C_{\bar{L}}^{\bar{H}}=C\left(E_{1}^{H}, E_{2}^{H}, E_{3}^{H}\right)-C\left(E_{1}^{L}, E_{2}^{L}, E_{3}^{L}\right) .
\end{gathered}
$$

Using a similar notation, the decomposition of Stein and Alpert (1993) applied to two variables $\left(E_{1}\right.$ and $\left.E_{2}\right)$ would read as

$\Delta C_{\overline{\mathrm{L}}}^{\mathrm{H}_{1}, \mathrm{H}_{2}}=\Delta C_{\overline{\mathrm{L}}}^{\mathrm{H}_{1}}+\Delta C_{\overline{\mathrm{L}}}^{\mathrm{H}_{2}}+\hat{C}^{\mathrm{int}}$,

where $\Delta C_{\overline{\mathrm{L}}}^{\mathrm{H}_{1}}$ and $\Delta C_{\overline{\mathrm{L}}}^{\mathrm{H}_{2}}$ are the impacts induced by the change in emission sources $E_{1}$ and $E_{2}$ taken independently, and $\Delta C_{\overline{\mathrm{L}}}^{\mathrm{H}_{1}, \mathrm{H}_{2}}$ is the impact induced from $E_{1}$ and $E_{2}$ taken simultaneously.

It is clear from Eq. (3) that the impact of a simultaneous change of two emission sources is not equivalent to the sum of the individual impacts, as highlighted by the additional term $\hat{C}^{\text {int }}$. This term, which quantifies the interaction between the two emission sources, can be calculated using Eq. (3) as

$\hat{C}^{\text {int }}=\hat{C}_{\overline{\mathrm{L}}}^{\mathrm{H}_{1}, \mathrm{H}_{2}}=\Delta C_{\overline{\mathrm{L}}}^{\mathrm{H}_{1}, \mathrm{H}_{2}}-\Delta C_{\overline{\mathrm{L}}}^{\mathrm{H}_{1}}-\Delta C_{\overline{\mathrm{L}}}^{\mathrm{H}_{2}}$.

The Stein-Alpert formulation can similarly be applied with three emission sources:

$\Delta C_{\overline{\mathrm{L}}}^{\overline{\mathrm{H}}}=\Delta C_{\overline{\mathrm{L}}}^{\mathrm{H}_{1}}+\Delta C_{\overline{\mathrm{L}}}^{\mathrm{H}_{2}}+\Delta C_{\overline{\mathrm{L}}}^{\mathrm{H}_{3}}+\hat{C}^{\mathrm{int}}$,

where $\Delta C_{\overline{\mathrm{L}}}^{\mathrm{H}_{1}}, \Delta C_{\overline{\mathrm{L}}}^{\mathrm{H}_{2}}$ and $\Delta C_{\overline{\mathrm{L}}}^{\mathrm{H}_{3}}$ are the impact on concentration resulting from single emission changes in the sources and

$\hat{C}^{\text {int }}=\hat{C}_{\overline{\mathrm{L}}}^{\mathrm{H}_{1}, \mathrm{H}_{2}}+\hat{C}_{\overline{\mathrm{L}}}^{\mathrm{H}_{1}, \mathrm{H}_{3}}+\hat{C}_{\overline{\mathrm{L}}}^{\mathrm{H}_{2}, \mathrm{H}_{3}}+\hat{C}_{\overline{\mathrm{L}}}^{\mathrm{H}_{1}, \mathrm{H}_{2}, \mathrm{H}_{3}}$,

where $\hat{C}_{\overline{\mathrm{L}}}^{\mathrm{H}_{1}, \mathrm{H}_{2}}, \hat{C}_{\overline{\mathrm{L}}}^{\mathrm{H}_{1}, \mathrm{H}_{3}}$ and $\hat{C}_{\overline{\mathrm{L}}}^{\mathrm{H}_{2}, \mathrm{H}_{3}}$ are the double interaction terms that can be further decomposed via Eq. (4). $\hat{C}_{\overline{\mathrm{L}}}^{\mathrm{H}_{1}, \mathrm{H}_{2}, \mathrm{H}_{3}}$ is the triple interaction term (between $E_{1}, E_{2}, E_{3}$ ), which can be decomposed by combining Eqs. (5) and (6) as

$$
\begin{aligned}
\hat{C}_{\overline{\mathrm{L}}}^{\mathrm{H}_{1}, \mathrm{H}_{2}, \mathrm{H}_{3}} & =\Delta C_{\overline{\mathrm{L}}}^{\overline{\mathrm{H}}}-\Delta C_{\overline{\mathrm{L}}}^{\mathrm{H}_{1}}-\Delta C_{\overline{\mathrm{L}}}^{\mathrm{H}_{2}}-\Delta C_{\overline{\mathrm{L}}}^{\mathrm{H}_{3}} \\
& -\Delta C_{\overline{\mathrm{L}}}^{\mathrm{H}_{1}, \mathrm{H}_{2}}-\Delta C_{\overline{\mathrm{L}}}^{\mathrm{H}_{1}, \mathrm{H}_{3}}-\Delta C_{\overline{\mathrm{L}}}^{\mathrm{H}_{2}, \mathrm{H}_{3}} .
\end{aligned}
$$

\subsection{Top-down formulation}

In a top-down formulation, the highest emission level is chosen as reference. The Stein-Alpert formulation for three precursors can then be expressed similarly to the bottom-up formulation as

$\Delta C_{\overline{\mathrm{L}}}^{\overline{\mathrm{H}}}=\Delta C_{\mathrm{L}_{1}}^{\overline{\mathrm{H}}}+\Delta C_{\mathrm{L}_{2}}^{\overline{\mathrm{H}}}+\Delta C_{\mathrm{L}_{3}}^{\overline{\mathrm{H}}}+\hat{C}^{\mathrm{int}}$,

where $\Delta C_{\mathrm{L}_{1}}^{\overline{\mathrm{H}}}, \Delta C_{\mathrm{L}_{2}}^{\overline{\mathrm{H}}}$ and $\Delta C_{\mathrm{L}_{3}}^{\overline{\mathrm{H}}}$ are the impacts on concentration induced by reducing $E_{1}, E_{2}$ and $E_{3}$ independently, whereas $\hat{C}^{\text {int }}$ is the interaction term, which itself can be decomposed into a series of double interactions and a triple interaction term:

$\hat{C}^{\text {int }}=\hat{C}_{\mathrm{L}_{1}, \mathrm{~L}_{2}}^{\overline{\mathrm{H}}}+\hat{C}_{\mathrm{L}_{1}, \mathrm{~L}_{3}}^{\overline{\mathrm{H}}}+\hat{C}_{\mathrm{L}_{2}, \mathrm{~L}_{3}}^{\overline{\mathrm{H}}}+\hat{C}_{\mathrm{L}_{1}, \mathrm{~L}_{2}, \mathrm{~L}_{3}}^{\overline{\mathrm{H}}}$.

It is important to stress that the top-down single impacts are not equivalent to their bottom-up counterparts. The relation between these bottom-up and top-down impacts can be expressed as (here for the case of $E_{3}$ )

$$
\begin{aligned}
\Delta C_{\mathrm{L}_{3}}^{\overline{\mathrm{H}}} & =C\left(E_{1}^{\mathrm{H}}, E_{2}^{\mathrm{H}}, E_{3}^{\mathrm{H}}\right)-C\left(E_{1}^{\mathrm{H}}, E_{2}^{\mathrm{H}}, E_{3}^{\mathrm{L}}\right), \\
\Delta C_{\mathrm{L}_{3}}^{\overline{\mathrm{H}}} & =C\left(E_{1}^{\mathrm{H}}, E_{2}^{\mathrm{H}}, E_{3}^{\mathrm{H}}\right)-C\left(E_{1}^{\mathrm{L}}, E_{2}^{\mathrm{L}}, E_{3}^{\mathrm{L}}\right) \\
& -\left[C\left(E_{1}^{\mathrm{H}}, E_{2}^{\mathrm{H}}, E_{3}^{\mathrm{L}}\right)-C\left(E_{1}^{\mathrm{L}}, E_{2}^{\mathrm{L}}, E_{3}^{\mathrm{L}}\right)\right], \\
\Delta C_{\mathrm{L}_{3}}^{\overline{\mathrm{H}}} & =\Delta C_{\overline{\mathrm{L}}}^{\overline{\mathrm{H}}}-\Delta C_{\overline{\mathrm{L}}}^{\mathrm{H}_{1} \mathrm{H}_{2}} .
\end{aligned}
$$

Using Eqs. (3)-(6), Eq. (9) can be re-expressed as

$\Delta C_{\mathrm{L}_{3}}^{\overline{\mathrm{H}}}=\Delta C_{\overline{\mathrm{L}}}^{\mathrm{H}_{3}}+\hat{C}_{\overline{\mathrm{L}}}^{\mathrm{H}_{1}, \mathrm{H}_{3}}+\hat{C}_{\overline{\mathrm{L}}}^{\mathrm{H}_{2}, \mathrm{H}_{3}}+\hat{C}_{\overline{\mathrm{L}}}^{\mathrm{H}_{1}, \mathrm{H}_{2}, \mathrm{H}_{3}}$.

In other words, the top-down impact on concentration of an emission source (obtained by switching off the emission source while all others remain unchanged) is not equivalent to its bottom-up counterpart (obtained by switching on the emission source while all others are switched off). Equation (10) indeed clearly shows that additional interaction terms need to be considered. The implications resulting from these differences are highlighted in Sect. 5, in which some theoretical examples are described.

\section{Source apportionment and sensitivity analysis}

\subsection{Tagged species techniques}

Equation (2) shows that, when the relationship between concentration and several emission sources is linear, the contribution of a specific source (source apportionment) can be computed as the impact on concentration obtained by a full reduction of this source (sensitivity). Moreover, the sum of the impacts on concentration obtained by reduction of the single sources $\left(\Delta C_{0}^{\mathrm{BC}_{1}}+\Delta C_{0}^{\mathrm{BC}_{2}}+\Delta C_{0}^{\mathrm{BC}_{3}}\right)$ is equivalent to the impact on concentration resulting from a simultaneous abatement of all sources $\left(\Delta C_{0}^{\mathrm{BC}}\right)$. In such a case, the concentration impacts are equal to source contributions and source 
apportionment and sensitivity analysis lead to similar results. This is not the case, however, when the relationship between concentrations and emissions is nonlinear. In their approach, Stein and Alpert express the difference between the impact caused by a simultaneous abatement and the sum of the impacts caused by individual abatement as interactions between the different sources. The Stein-Alpert formulation applied between the $\mathrm{BC}$ and background levels is very close to Eq. (2) but with an additional term that accounts for interactions:

$\Delta C_{0}^{\mathrm{BC}}=\Delta C_{0}^{\mathrm{BC}_{1}}+\Delta C_{0}^{\mathrm{BC} C_{2}}+\Delta C_{0}^{\mathrm{BC}_{3}}+\hat{C}^{\mathrm{int}}$.

Because the interaction terms cannot be attributed to a single emission source as they represent the interaction between two or more emission sources, the Stein-Alpert methodology does not allow one to identify the full contribution of each individual source. It cannot therefore be used for source apportionment purpose, unless the interaction terms are negligible as in the linear case.

Unlike the Stein-Alpert methodology, the tagged species methodology is designed for source apportionment purposes. This methodology tags each precursor and quantifies its contribution (in terms of mass) to the pollutant concentration.

Tagged algorithms are implemented in several chemical transport model systems (Yarwood et al., 2004; Wagstrom et al., 2008; ENVIRON, 2014; Bhave et al., 2007; Wang et al., 2009; Kranenburg et al., 2013).

In tagging approaches, the effect of the full reduction of all sources is directly expressed as the sum of the source contributions:

$\Delta C_{0}^{\mathrm{BC}}=\delta C_{1}+\delta C_{2}+\delta C_{3}$,

where $\delta C_{1}, \delta C_{2}$ and $\delta C_{3}$ are the contributions of sources $E_{1}$, $E_{2}$ and $E_{3}$ resulting from the tagged species approach resolution.

Tagging methodologies split the interaction terms into fractions and attribute these fractions to the source contributions, on the basis of mass weighting factors:

$\delta C_{1}=\Delta C_{0}^{\mathrm{BC}_{1}}+\alpha \hat{C}^{\mathrm{int}}$.

Because the tagged species approach mixes interaction terms and single concentration impacts into sources contributions, it is not suitable to estimate the effect of emission reduction when nonlinearities are present (Burr and Zhang, 2011a, b). Indeed, these two types of terms may react in very different ways to emission reductions. This fact is detailed in the examples provided below.

On the other hand, the strength of this method is that it allows for a direct comparison of the source contributions with measurements (or measurement-based methods like receptor models).

Note that similar tagging methods are also used in the frame of climate-chemical studies at the global scale (e.g. Horowitz and Jacob, 1999; Lelieveld and Dentener, 2000; Meijer et al., 2000; Grewe, 2004; Gromov et al., 2010; Butler et al., 2011; Emmons et al., 2012; Grewe et al., 2012, 2017).

\subsection{DDM}

The decoupled direct method (DDM) is designed to calculate directly sensitivities to emission changes (Dunker et al., 1984, 2002). It aims to compute the first-order derivatives (which correspond to the potencies mentioned in Sect. 2):

$\frac{\partial C}{\partial E_{1}} ; \frac{\partial C}{\partial E_{2}} ; \frac{\partial C}{\partial E_{3}}$.

The Taylor formula is applied at first order to calculate the concentration change between two emission levels (denoted $\mathrm{H}$ and $\mathrm{L}$ ):

$\Delta C_{\overline{\mathrm{L}}}^{\overline{\mathrm{H}}}=\left.\Delta E_{1} \frac{\partial C}{\partial E_{1}}\right|_{\mathrm{H}}+\left.\Delta E_{2} \frac{\partial C}{\partial E_{2}}\right|_{\mathrm{H}}+\left.\Delta E_{3} \frac{\partial C}{\partial E_{3}}\right|_{\mathrm{H}}$

with $\Delta E_{1}=E_{1}^{\mathrm{H}}-E_{1}^{\mathrm{L}}, \Delta E_{2}=E_{2}^{\mathrm{H}}-E_{2}^{\mathrm{L}}, \Delta E_{3}=E_{3}^{\mathrm{H}}-E_{3}^{\mathrm{L}}$.

In the linear case, the first-order derivatives are constant and the first-order approximation of the Taylor formula gives the exact expression of the impact on concentration of an emission change between $\mathrm{H}$ and $\mathrm{L}$. When the emissionconcentration relationship is nonlinear, the first derivatives are not constants. The first-order Taylor formula cannot take into account the nonlinear effects. It is a linear approximation based on derivatives computed at a given emission reference level (level $\mathrm{H}$ in our example). The estimation of the impact on concentration of an emission change between $\mathrm{H}$ and $\mathrm{L}$ is accurate enough if level $\mathrm{L}$ is close enough to level $\mathrm{H}$.

HDDM is another method (Hakami et al., 2003) which aims to increase the accuracy of the DDM method by computing second-order derivatives.

DDM (and HDDM) gives similar information to the SteinAlpert formulation applied with the brute-force top-down approach (because the reference level is $\mathrm{H}$ ). For the same reason as for the Stein-Alpert approach, these two methods are suitable for source apportionment purpose only if the relation between concentration and emission is close to linearity.

DDM (and HDDM) approximates the impact on concentration from an emission change between the two levels $\mathrm{H}$ and $\mathrm{L}$, using derivatives computed at level $\mathrm{H}$. This impact is accurate enough if level $\mathrm{L}$ is close enough to the reference level $\mathrm{H}$.

Dunker (2015) showed how to use first-order sensitivity to determine source contributions between two model cases - e.g. to apportion the difference between the current atmosphere (and natural conditions) to specific human activities. Along the same lines, Simon et al. (2013) used first-order sensitivity to construct emission response surfaces. To cope with potential nonlinearities and the need to compute higherorder derivatives, a powerful alternative is to compute firstorder sensitivities at several emission levels. 


\section{Example}

In this section, examples are designed to illustrate the differences in terms of contribution and impact estimates when the approaches discussed previously are used. In these examples, we focus on the formation of PM in the atmosphere and only consider three formation processes: direct emissions (primary PM denoted as PPM), formation through reactions with nitrogen oxides $\left(\mathrm{NO}_{2}\right)$ and ammonia, $\left(\mathrm{NH}_{3}\right)$ and formation through reactions with sulfur oxide $\left(\mathrm{SO}_{2}\right)$ and $\mathrm{NH}_{3}$ :

$$
\begin{aligned}
& \mathrm{PPM} \rightarrow \mathrm{PM} \\
& 2 \mathrm{NO}_{2}+\mathrm{H}_{2} \mathrm{O}+\frac{1}{2} \mathrm{O}_{2} \rightarrow 2 \mathrm{HNO}_{3} \\
& 2 \mathrm{NH}_{3}+2 \mathrm{HNO}_{3} \rightarrow 2 \mathrm{NH}_{4} \mathrm{NO}_{3} \\
& \mathrm{SO}_{2}+\mathrm{H}_{2} \mathrm{O}+\frac{1}{2} \mathrm{O}_{2} \rightarrow \mathrm{H}_{2} \mathrm{SO}_{4} \\
& 2 \mathrm{NH}_{3}+\mathrm{H}_{2} \mathrm{SO}_{4} \rightarrow\left(\mathrm{NH}_{4}\right)_{2} \mathrm{SO}_{4} .
\end{aligned}
$$

These reactions pathways are summarised by the following system of reactions:

$$
\begin{aligned}
& \mathrm{PPM} \rightarrow \mathrm{PM}[\mathrm{PPM}] \\
& \mathrm{NO}_{2}+\mathrm{NH}_{3} \rightarrow \mathrm{PM}\left[\mathrm{NH}_{4} \mathrm{NO}_{3}\right] \\
& \mathrm{SO}_{2}+2 \mathrm{NH}_{3} \rightarrow \mathrm{PM}\left[\left(\mathrm{NH}_{4}\right)_{2} \mathrm{SO}_{4}\right] .
\end{aligned}
$$

This system is further simplified by assuming that all reactions have comparable kinetics (reaction speed) and have reached their equilibrium. From these three reactions, 1 PM mole can be produced by 1 PPM mole, by the combination of $1 \mathrm{NH}_{3}$ and $1 \mathrm{NO}_{2}$ moles or by the combination of $1 \mathrm{SO}_{2}$ and $2 \mathrm{NH}_{3}$ moles.

We also limit our examples to emissions from three activity sectors. The residential sector (R) only emits PPM and $\mathrm{NO}_{2}$, the agricultural sector (A) only emits $\mathrm{NH}_{3}$ and the industrial sector (I) only emits PPM and $\mathrm{SO}_{2}$ (Fig. 1). We assume for convenience that no background pollution is present (i.e. there is no PM when all emissions are zero). Two situations are considered: a "non-limited regime" where the $\mathrm{NH}_{3}$ quantity is sufficient to react with all moles of $\mathrm{NO}_{2}$ and $\mathrm{SO}_{2}$ and a "limited regime" where the $\mathrm{NH}_{3}$ quantity is not sufficient to react with all moles of $\mathrm{NO}_{2}$ and $\mathrm{SO}_{2}$.

\subsection{Non-limited regime}

In this first example, the quantity of precursors (in terms of mass) is large enough to feed all reactions. The agricultural sector emits $150 \mathrm{NH}_{3}$ moles, which can react with $50 \mathrm{NO}_{2}$ moles emitted by the residential sector and $50 \mathrm{SO}_{2}$ moles emitted by industrial sector. One hundred PPM moles are emitted by the residential sector as well by the industrial sector (Fig. 1).

Let us first calculate the PM concentration produced with and without each of the sources:

- No source:

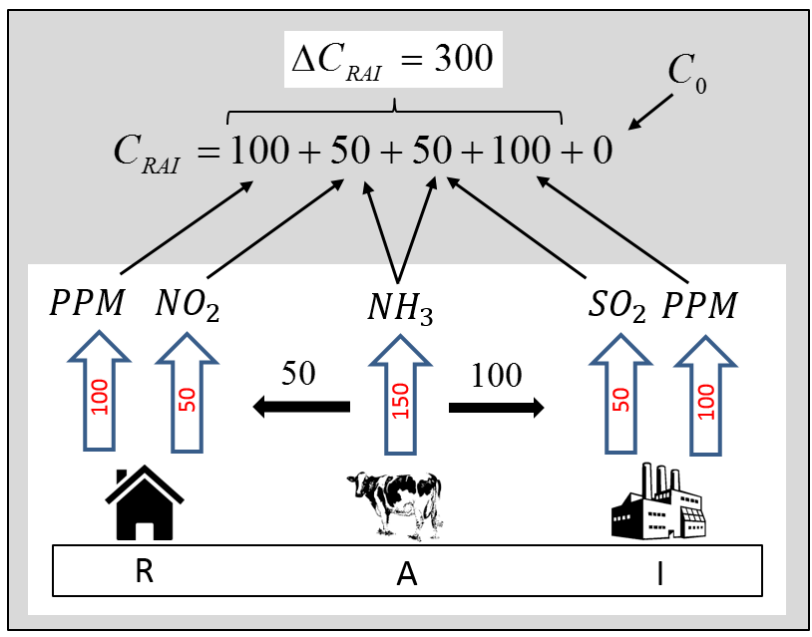

Figure 1. Example of $\mathrm{PPM}, \mathrm{NO}_{2}, \mathrm{SO}_{2}$ and $\mathrm{NH}_{3}$ emissions released by three activity sectors: residential (R), agricultural (A) and industrial (I). For convenience, no units are associated with emissions and concentrations.

$C_{0}$ is the PM concentration obtained when all emissions are set to zero. Since we assumed a zero background pollution, $C_{0}=0$.

- One source only:

$C_{\mathrm{R}}$ (resp. $C_{\mathrm{A}}$ and $C_{\mathrm{I}}$ ) is the $\mathrm{PM}$ concentration reached when only the residential (resp. agricultural and industrial) sector releases emissions:

- $C_{\mathrm{R}}=100$ produced by PPM emissions ( $\mathrm{NO}_{2}$ emissions do not produce $\mathrm{PM}$ as no $\mathrm{NH}_{3}$ is available).

- $C_{\mathrm{A}}=0$ because $\mathrm{NO}_{2}$ and $\mathrm{SO}_{2}$ are not available to react with $\mathrm{NH}_{3}$.

- $C_{\mathrm{I}}=100$ produced by the PPM emissions $\left(\mathrm{SO}_{2}\right.$ emissions do not produce $\mathrm{PM}$ as no $\mathrm{NH}_{3}$ is available).

- Two sources:

$C_{\mathrm{RA}} C_{\mathrm{RI}}$, and $C_{\mathrm{AI}}$ are the concentrations obtained when two (out of three) activity sectors release their emissions simultaneously (the RA subscripts correspond to residential and agriculture, RI to residential and industrial, AI to agriculture and industrial):

- $C_{\mathrm{RA}}=150: 100$ produced by PPM emissions from the residential sector and 50 produced by the 50 $\mathrm{NO}_{2}$ released by the residential sector reacting with the $50 \mathrm{NH}_{3}$ emitted by agriculture $\left(100 \mathrm{NH}_{3}\right.$ moles remain unused).

- $C_{\mathrm{RI}}=200: 100$ produced by PPM emissions from the residential sector and 100 produced by PPM emissions from the industrial sector. 
- $C_{\mathrm{AI}}=150: 100$ produced by PPM industrial emissions and 50 from the combination of $50 \mathrm{SO}_{2}$ (industry) and $100 \mathrm{NH}_{3}$ (agriculture).

- Three sources:

$C_{\mathrm{RAI}}$ is the concentrations obtained when all emissions are released simultaneously.

$-C_{\mathrm{RAI}}=300: 200$ from PPM (residential and industry), 50 from reaction between $\mathrm{NO}_{2}$ and $\mathrm{NH}_{3}$ and 50 from reaction between $\mathrm{SO}_{2}$ and $\mathrm{NH}_{3}$.

\subsubsection{Brute-force bottom-up (BF-BU) method}

The contribution of each activity sector is calculated as the concentration change resulting from a $100 \%$ emission increase from the lowest emission level (previously denoted "L" or background) to the highest level (denoted as " $\mathrm{H}$ "; the $\mathrm{BC} C_{\mathrm{RAI}}$ obtained with all emissions).

In a bottom-up approach, the concentration associated with the lowest emission level is considered as the reference. Concentration impacts are then computed by the difference between any situation (e.g. one, two or three sources present) and this reference:

- With one source:

$$
\begin{aligned}
& \Delta C_{\mathrm{R}}^{\mathrm{BU}}=C_{\mathrm{R}}-C_{0}=100 \\
& \Delta C_{\mathrm{A}}^{\mathrm{BU}}=C_{\mathrm{A}}-C_{0}=0 \\
& \Delta C_{\mathrm{I}}^{\mathrm{BU}}=C_{\mathrm{I}}-C_{0}=100 .
\end{aligned}
$$

- With two sources:

$$
\begin{aligned}
\Delta C_{\mathrm{RA}}^{\mathrm{BU}} & =C_{\mathrm{RA}}-C_{0}=150 \\
\Delta C_{\mathrm{RI}}^{\mathrm{BU}} & =C_{\mathrm{RI}}-C_{0}=200 \\
\Delta C_{\mathrm{AI}}^{\mathrm{BU}} & =C_{\mathrm{AI}}-C_{0}=150 .
\end{aligned}
$$

- With three sources:

$$
\Delta C_{\mathrm{RAI}}=C_{\mathrm{RAI}}-C_{0}=300 .
$$

To calculate the interaction terms, we use the Stein-Alpert formulation using Eqs. (5) and (6):

$\Delta C_{\mathrm{RAI}}=\Delta C_{\mathrm{R}}^{\mathrm{BU}}+\Delta C_{\mathrm{A}}^{\mathrm{BU}}+\Delta C_{\mathrm{I}}^{\mathrm{BU}}+\hat{C}_{\mathrm{RA}}^{\mathrm{BU}}+\hat{C}_{\mathrm{RI}}^{\mathrm{BU}}+\hat{C}_{\mathrm{AI}}^{\mathrm{BU}}+\hat{C}_{\mathrm{RAI}}^{\mathrm{BU}}$ from which the interaction terms are obtained by application of Eqs. (4) and (6):

$\hat{C}_{\mathrm{RA}}^{\mathrm{BU}}=\Delta C_{\mathrm{RA}}^{\mathrm{BU}}-\Delta C_{\mathrm{R}}^{\mathrm{BU}}-\Delta C_{\mathrm{A}}^{\mathrm{BU}}=50$

$\hat{C}_{\mathrm{RI}}^{\mathrm{BU}}=\Delta C_{\mathrm{RI}}^{\mathrm{BU}}-\Delta C_{\mathrm{R}}^{\mathrm{BU}}-\Delta C_{\mathrm{I}}^{\mathrm{BU}}=0$

$\hat{C}_{\mathrm{AI}}^{\mathrm{BU}}=\Delta C_{\mathrm{AI}}^{\mathrm{BU}}-\Delta C_{\mathrm{A}}^{\mathrm{BU}}-\Delta C_{\mathrm{I}}^{\mathrm{BU}}=50$

$\hat{C}_{\mathrm{RAI}}^{\mathrm{BU}}=\Delta C_{\mathrm{RAI}}-\Delta C_{\mathrm{R}}^{\mathrm{BU}}-\Delta C_{\mathrm{A}}^{\mathrm{BU}}-\Delta C_{\mathrm{I}}^{\mathrm{BU}}-\hat{C}_{\mathrm{RA}}^{\mathrm{BU}}$

$$
-\hat{C}_{\mathrm{RI}}^{\mathrm{BU}}-\hat{C}_{\mathrm{AI}}^{\mathrm{BU}}=0 .
$$

As can be seen from this example, the system behaves nonlinearly and the interaction terms (e.g. $\hat{C}_{\mathrm{RA}}^{\mathrm{BU}}$ ) are non- zero. Moreover, the sum of the individual impacts $\left(\Delta C_{\mathrm{R}}^{\mathrm{BU}}+\right.$ $\left.\Delta C_{\mathrm{A}}^{\mathrm{BU}}+\Delta C_{\mathrm{I}}^{\mathrm{BU}}=200\right)$ underestimates the overall impact $\left(\Delta C_{\mathrm{RAI}}=300\right)$. These results are graphically represented in Fig. 2 (third column).

\subsubsection{Brute-force top-down (BF-TD) method}

In a BF-TD approach, the higher emission level (base case, $\left.C_{\mathrm{RAI}}\right)$ is the reference and the impact of each activity sector is calculated as the concentration change resulting from a $100 \%$ emission decrease (of one, two or three sources) from this reference to the background level:

- With one source:

When all emissions from one sector are reduced (e.g. residential), the other two sector remain active (agricultural and industry). In this case, the top-down impact is the difference between the base case concentration and the concentration resulting from the agricultural and industrial emissions only. A similar reasoning can be made for all sectors:

$$
\begin{aligned}
& \Delta C_{\mathrm{R}}^{\mathrm{TD}}=C_{\mathrm{RAI}}-C_{\mathrm{AI}}=150 \\
& \Delta C_{\mathrm{A}}^{\mathrm{TD}}=C_{\mathrm{RAI}}-C_{\mathrm{RI}}=100 \\
& \Delta C_{\mathrm{I}}^{\mathrm{TD}}=C_{\mathrm{RAI}}-C_{\mathrm{RA}}=150 .
\end{aligned}
$$

- With two sources:

The top-down impact due to a full reduction of two sectors (e.g. residential and agriculture) is similarly computed as the difference between the base case concentration and the concentration resulting from the remaining sector (industry):

$$
\begin{aligned}
& \Delta C_{\mathrm{RA}}^{\mathrm{TD}}=C_{\mathrm{RAI}}-C_{\mathrm{I}}=200 \\
& \Delta C_{\mathrm{RI}}^{\mathrm{TD}}=C_{\mathrm{RAI}}-C_{\mathrm{A}}=300 \\
& \Delta C_{\mathrm{AI}}^{\mathrm{TD}}=C_{\mathrm{RAI}}-C_{R}=200 .
\end{aligned}
$$

\section{- With three sources:}

The impact resulting from the simultaneous reduction of all three sources is similar in the top-down and bottomup approaches:

$$
\Delta C_{\mathrm{RAI}}=C_{\mathrm{RAI}}-C_{0}=300 .
$$

The interaction terms can be obtained in a similar way to the bottom-up approach by using the Stein-Alpert formulation for $\Delta C_{\mathrm{RAI}}$

$$
\Delta C_{\mathrm{RAI}}=\Delta C_{\mathrm{R}}^{\mathrm{TD}}+\Delta C_{\mathrm{A}}^{\mathrm{TD}}+\Delta C_{\mathrm{I}}^{\mathrm{TD}}+\hat{C}_{\mathrm{RA}}^{\mathrm{TD}}+\hat{C}_{\mathrm{RI}}^{\mathrm{TD}}+\hat{C}_{\mathrm{AI}}^{\mathrm{TD}}+\hat{C}_{\mathrm{RAI}}^{\mathrm{TD}} \cdot
$$




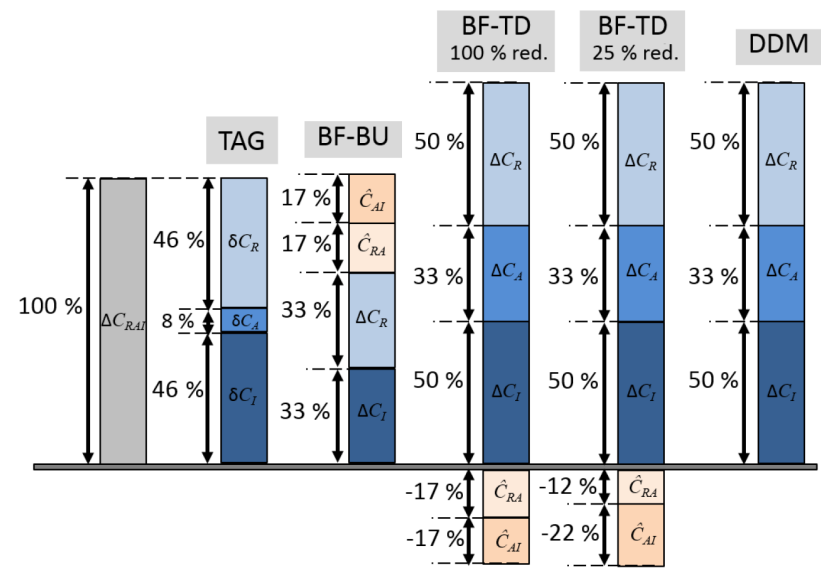

Figure 2. Schematic representation of the allocation of PM to its sources in the non-limited example. The expected total PM is displayed in the grey bar on the left.

The interaction terms are given by

$$
\begin{aligned}
\hat{C}_{\mathrm{RA}}^{\mathrm{TD}} & =\Delta C_{\mathrm{RA}}^{\mathrm{TD}}-\Delta C_{\mathrm{R}}^{\mathrm{TD}}-\Delta C_{\mathrm{A}}^{\mathrm{TD}}=-50 \\
\hat{C}_{\mathrm{RI}}^{\mathrm{TD}} & =\Delta C_{\mathrm{RI}}^{\mathrm{TD}}-\Delta C_{\mathrm{R}}^{\mathrm{TD}}-\Delta C_{\mathrm{I}}^{\mathrm{TD}}=0 \\
\hat{C}_{\mathrm{AI}}^{\mathrm{TD}} & =\Delta C_{\mathrm{AI}}^{\mathrm{TD}}-\Delta C_{\mathrm{A}}^{\mathrm{TD}}-\Delta C_{\mathrm{I}}^{\mathrm{TD}}=-50 \\
\hat{C}_{\mathrm{RAI}}^{\mathrm{TD}} & =\Delta C_{\mathrm{RAI}}-\Delta C_{\mathrm{R}}^{\mathrm{TD}}-\Delta C_{\mathrm{A}}^{\mathrm{TD}}-\Delta C_{\mathrm{I}}^{\mathrm{TD}}-\hat{C}_{\mathrm{RA}}^{\mathrm{TD}} \\
& -\hat{C}_{\mathrm{RI}}^{\mathrm{TD}}-\hat{C}_{\mathrm{AI}}^{\mathrm{TD}}=0 .
\end{aligned}
$$

With this approach, a nonlinear behaviour is also observed and interaction terms are non-zero. It is also interesting to note that the triple interaction term $\left(\hat{C}_{\mathrm{RAI}}^{\mathrm{TD}}\right)$ is null. The sum of the individual impacts $\left(\Delta C_{\mathrm{R}}^{\mathrm{TD}}+\Delta C_{\mathrm{A}}^{\mathrm{TD}}+\Delta C_{\mathrm{I}}^{\mathrm{TD}}=400\right)$ overestimates the overall impact $\left(\Delta C_{\mathrm{RAI}}=300\right)$. We further discuss these aspects at the end of this section. These results are graphically represented in Fig. 2 (fourth and fifth columns).

\subsubsection{Tagged species approach}

Compared to brute force, the tagged species approach calculates the share of each source to the overall concentration change. These shares are referred to as contributions and have the main property that the sum of the individual contributions is equal to the overall concentration impact, by definition, i.e.

$$
\Delta C_{\mathrm{RAI}}=\delta C_{\mathrm{R}}^{\mathrm{TAG}}+\delta C_{\mathrm{A}}^{\mathrm{TAG}}+\delta C_{\mathrm{I}}^{\mathrm{TAG}} .
$$

The sector contributions are computed by tracking the mass of their emitted species contributing to PM formation (in our example: PM[PPM], PM $\left[\mathrm{NH}_{4} \mathrm{NO}_{3}\right]$ and PM $\left.\left[\left(\mathrm{NH}_{4}\right)_{2} \mathrm{SO}_{4}\right]\right)$ :

- PM[PPM] is formed from PPM. The $100 \mathrm{~mol}$ from the residential sector lead to $100 \mathrm{~mol}$ of PM. The same applies to the $100 \mathrm{~mol}$ from industry.
- $\mathrm{PM}\left[\mathrm{NH}_{4} \mathrm{NO}_{3}\right]$ is formed by combination of $\mathrm{NH}_{3}$ and $\mathrm{NO}_{2}$. The share between these two contributions is obtained by application of stoichiometric molar mass ratios:

$$
a_{1}=\frac{\left[\mathrm{NO}_{3}\right]_{m}}{\left[\mathrm{NO}_{3}\right]_{m}+\left[\mathrm{NH}_{4}\right]_{m}}=0.78
$$

In our example, $50 \mathrm{~mol}$ of $\mathrm{PM}\left[\mathrm{NH}_{4} \mathrm{NO}_{3}\right]$ are formed by combination of $\mathrm{NO}_{2}(50 \mathrm{~mol})$ from the residential sector and $\mathrm{NH}_{3}(50 \mathrm{~mol})$ from agriculture. The contribution attributed to $\mathrm{NO}_{2}$ is $50 \times a_{1}$, whereas the contribution attributed to $\mathrm{NH}_{3}$ is $50 \times\left(1-a_{1}\right)$.

- PM[ $\left[\left(\mathrm{NH}_{4}\right)_{2} \mathrm{SO}_{4}\right]$ is formed by combination of $\mathrm{NH}_{3}$ and $\mathrm{SO}_{2}$. The following stoichiometric mass ratio is used:

$$
a_{2}=\frac{\left[\mathrm{SO}_{4}\right]_{m}}{\left[\mathrm{SO}_{4}\right]_{m}+2\left[\mathrm{NH}_{4}\right]_{m}}=0.73 .
$$

The contribution attributed to $\mathrm{SO}_{2}$ is $50 \times a_{2}$, whereas the contribution attributed to $\mathrm{NH}_{3}$ is $50 \times\left(1-a_{2}\right)$.

The contribution of each sector is then obtained as the sum of their precursor contribution shares as follows:

$\delta C_{\mathrm{R}}^{\mathrm{TAG}}=100+50 \times a_{1}=138.7$

$\delta C_{\mathrm{A}}^{\mathrm{TAG}}=50 \times\left(1-a_{1}\right)+50 \times\left(1-a_{2}\right)=24.9$

$\delta C_{\mathrm{I}}^{\mathrm{TAG}}=100+50 \times a_{2}=136.4$.

By definition the sum of the contributions $\left(\delta C_{\mathrm{R}}^{\mathrm{TAG}}+\delta C_{\mathrm{A}}^{\mathrm{TAG}}+\right.$ $\left.\delta C_{\mathrm{I}}^{\mathrm{TAG}}=300\right)$ is exactly equal to the overall concentration impact $\left(\triangle C_{\mathrm{RAI}}=300\right)$

Note that a decomposition of the nonlinear interaction terms obtained in the top-down or bottom-up approach (using the above stoichiometric ratios) would lead to similar results as for the tagged approach. These results are graphically represented in Fig. 2 (second column).

\subsubsection{DDM}

In this methodology, delta concentrations and interaction terms are estimated with first-order partial derivatives computed from the highest emission level (base case in our example). Being a sensitivity approach using level $\mathrm{H}$ as reference, DDM shows clear analogies with the BF-TD:

$\left.\frac{\partial C}{\partial \alpha_{\mathrm{R}}}\right|_{\mathrm{TD}}=150,\left.\quad \frac{\partial C}{\partial \alpha_{\mathrm{A}}}\right|_{\mathrm{TD}}=100,\left.\quad \frac{\partial C}{\partial \alpha_{\mathrm{I}}}\right|_{\mathrm{TD}}=150$,

where $\alpha_{\mathrm{R}}, \alpha_{\mathrm{A}}$ and $\alpha_{\mathrm{I}}$ are percentage emission changes from the $\mathrm{BC}$ for the residential, agricultural and industrial sectors.

The first-order derivatives are evaluated using finite differencing between the $\mathrm{BC}$ and a level characterised by emissions that are $10 \%$ lower for each activity sector. 
The concentration changes resulting from a $100 \%$ emission reduction (i.e. between the $\mathrm{BC}$ and the zero emission case) can be estimated by setting $\alpha_{\mathrm{R}}, \alpha_{\mathrm{A}}$ and $\alpha_{\mathrm{I}}$ to unity:

$$
\begin{aligned}
& \Delta C_{\mathrm{R}}^{\mathrm{HDDM}}=\left.\frac{\partial C}{\partial \alpha_{\mathrm{R}}}\right|_{\mathrm{TD}}=150 \\
& \Delta C_{\mathrm{A}}^{\mathrm{HDDM}}=\left.\frac{\partial C}{\partial \alpha_{\mathrm{A}}}\right|_{\mathrm{TD}}=100 \\
& \Delta C_{\mathrm{I}}^{\mathrm{HDDM}}=\left.\frac{\partial C}{\partial \alpha_{\mathrm{I}}}\right|_{\mathrm{TD}}=150 .
\end{aligned}
$$

We see from this last example that both the total PM and the contribution of the sources are then comparable with those obtained by the BF-TD method. Their interpretation is similar (Fig. 2, sixth column). In their work, Koo et al. (2009) present a detailed comparison between a DDM and a tagged species approach in a 3-D PM model and show which sensitivities are similar to apportionment, and which are not.

\subsubsection{Comparative overview}

In the linear case (second paragraph) we have seen that a single source contribution can be computed as the impact resulting from a full reduction of this source. However, source contributions and concentration impacts should not be confused as they are different in most situations. The example presented in this paragraph illustrates this clearly for a nonlinear system. Indeed the contributions of the single sources computed by the tagged species approach $\left(\delta C_{\mathrm{R}}^{\mathrm{TAG}}=138\right.$; $\left.\delta C_{\mathrm{A}}^{\mathrm{TAG}}=24 ; \delta C_{\mathrm{I}}^{\mathrm{TAG}}=136\right)$ differ from the concentration impacts resulting from a total abatement of these single sources computed by the BF-TD $\left(\Delta C_{\mathrm{R}}^{\mathrm{TD}}=150 ; \Delta C_{\mathrm{A}}^{\mathrm{TD}}=\right.$ $\left.100 ; \Delta C_{\mathrm{I}}^{\mathrm{TD}}=150\right)$ method. Moreover, the sum of the concentration impacts obtained with either the BF-TD or BF$\mathrm{BU}$ approach for single sources does not equal the total concentration impact $\left(\Delta C_{\mathrm{RAI}}=300\right)$. This is also valid for any selection of two sectors $\left(\Delta C_{\mathrm{R}}^{\mathrm{TD}}+\Delta C_{\mathrm{A}}^{\mathrm{TD}}=250 \neq \Delta C_{\mathrm{RA}}^{\mathrm{TD}}=\right.$ $200)$. Note that similarly to BF-TD, the concentration impacts computed as increases from the background (BF-BU) show the same behaviour $\left(\Delta C_{\mathrm{R}}^{\mathrm{BU}}+\Delta C_{\mathrm{A}}^{\mathrm{BU}}=100 \neq \Delta C_{\mathrm{RA}}^{\mathrm{BU}}=\right.$ 150).

Figure 3 shows that the impact on concentration is proportional to the emission reduction indicating that the relationship between emission and concentration changes is linear. However, this example also illustrates the fact that linearity encompasses two aspects: (1) the interaction terms are zero $\left(\hat{C}^{\text {int }}=0\right)$ and (2) the ratios between concentration change and emission changes $(\Delta C / \Delta E)$ remain constant, regardless of the calculation bounds (denoted " $\mathrm{H}$ " and "L" in Sect. 4). In the current example the ratios $\Delta C / \Delta E$ are constant (linear trend of $\Delta C$ in Fig. 3) but the relationship between concentration and emission is not linear because of the non-zero interaction terms (not shown) $\left(\hat{C}_{\mathrm{RA}}^{\mathrm{TD}}=-50\right.$ and $\hat{C}_{\mathrm{AI}}^{\mathrm{TD}}=-50$ ). However, even with zero interaction terms, we can still observe a nonlinear behaviour with the emission reduction per-

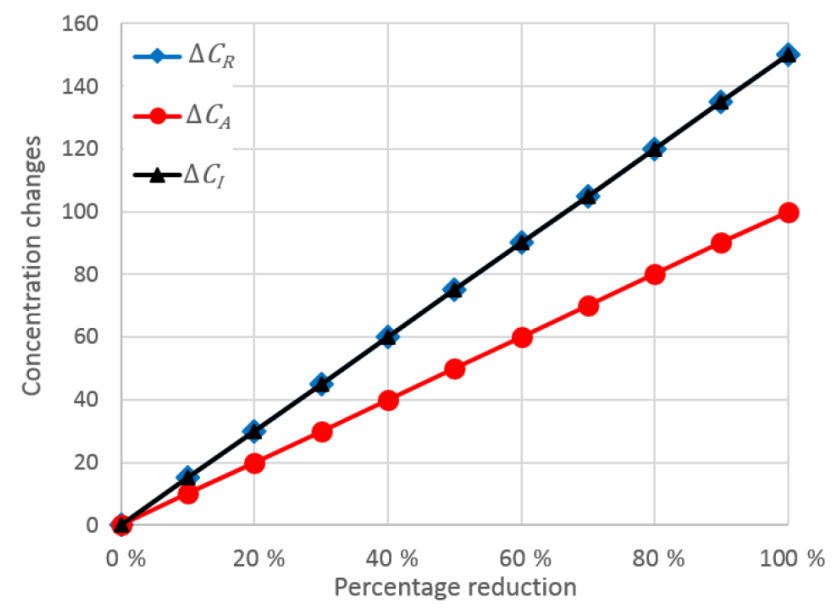

Figure 3. Evolution of the concentration changes resulting from different percentage of source abatement (top-down approach) for the three sectors (residential, agricultural and industrial).

centage. The evaluation of linearity therefore requires two tests: one to quantify the interaction terms and the second to assess the deviation from a linear trend with respect to the emission reduction percentage.

\subsection{Limited regime}

This example is similar to the previous one, except that the emissions of $\mathrm{NH}_{3}$ are reduced from 150 to $100 \mathrm{~mol}$.

When all sources release emissions, the $100 \mathrm{~mol}$ of $\mathrm{NH}_{3}$ are split into $100 / 3=33.3 \mathrm{~mol}$ which react with $\mathrm{NO}_{2}$ to form $33.3 \mathrm{~mol}$ of $\mathrm{PM}\left[\mathrm{NH}_{4} \mathrm{NO}_{3}\right]$ and $100 \times 2 / 3=66.6 \mathrm{~mol}$ which react with $\mathrm{SO}_{2}$ to give $33.3 \mathrm{~mol}$ of $\mathrm{PM}\left[\left(\mathrm{NH}_{4}\right)_{2} \mathrm{SO}_{4}\right]$. Because the mass of $\mathrm{NH}_{3}$ is not enough to react with all the $\mathrm{NO}_{2}$ and $\mathrm{SO}_{2}$ mass, $16.7 \mathrm{~mol}$ of $\mathrm{NO}_{2}$ and $16.7 \mathrm{~mol}$ of $\mathrm{SO}_{2}$ remain unused (Fig. 4).

Note that when the agricultural source is active with only one of the two other sources (residential or industrial), the $\mathrm{NH}_{3} 100 \mathrm{~mol}$ are then sufficient to consume all the $\mathrm{NO}_{2}$ or $\mathrm{SO}_{2}$ and lead to $50 \mathrm{~mol}$ of $\mathrm{PM}$ in either case.

The PM concentrations obtained when one or two sources are active are similar to the previous example:

$C_{0}=0 ; \quad C_{\mathrm{R}}=100 ; \quad C_{\mathrm{A}}=0 ; \quad C_{\mathrm{I}}=100$

$C_{\mathrm{RA}}=150 ; \quad C_{\mathrm{RI}}=200 ; \quad C_{\mathrm{AI}}=150$.

But the result differ when all sources are active: $C_{\mathrm{RAI}}=$ 266.6 (200 from PPM (residential industry), 33.3 from reaction between $\mathrm{NO}_{2}$ and $\mathrm{NH}_{3}$ and 33.3 from reaction between $\mathrm{SO}_{2}$ and $\mathrm{NH}_{3}$ ).

\subsubsection{Bottom-up brute-force method (BF-BU)}

The BF-BU approach computes all concentration impacts from the background concentration $\left(C_{0}\right)$. The Stein-Alpert terms are similar to the non-limited case, except for $\Delta C_{\mathrm{RAI}}$ 


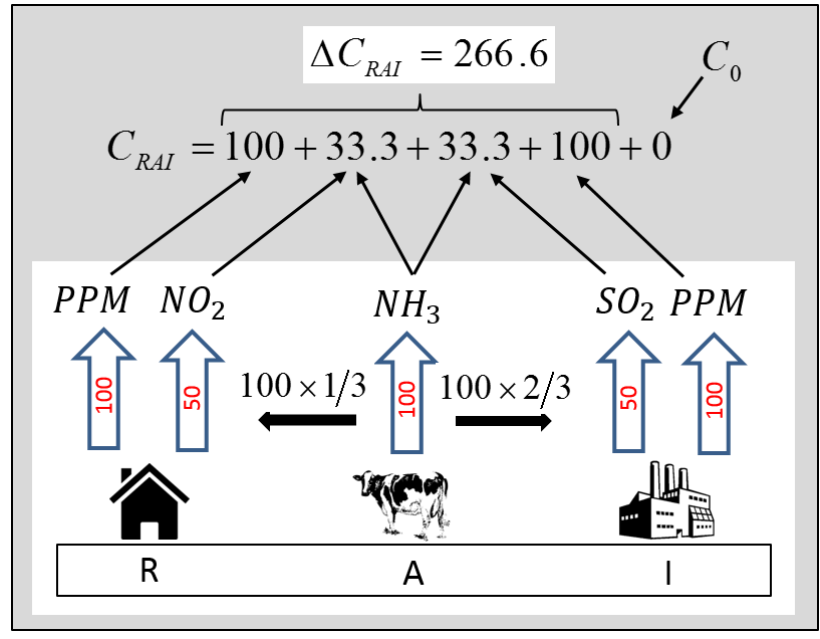

Figure 4. Example with three sources in an ammonia-limited regime. The mass emitted by each source is expressed in moles.

and $\hat{C}_{\text {RAI }}$ :

$\Delta C_{\mathrm{R}}^{\mathrm{BU}}=100, \quad \hat{C}_{\mathrm{RA}}^{\mathrm{BU}}=50$,

$\Delta C_{\mathrm{A}}^{\mathrm{BU}}=0, \quad \hat{C}_{\mathrm{RI}}^{\mathrm{BU}}=0$,

$\Delta C_{\mathrm{I}}^{\mathrm{BU}}=100, \quad \hat{C}_{\mathrm{AI}}^{\mathrm{BU}}=50$,

$\Delta C_{\mathrm{RAI}}=266.6, \quad \hat{C}_{\mathrm{RAI}}=-33.3$.

The limiting effect of $\mathrm{NH}_{3}$ appears only in the negative triple interaction term $\left(\hat{C}_{\mathrm{RAI}}\right)$. These results are graphically represented in Fig. 5 (third column).

\subsubsection{Top-down brute-force method (BF-TD)}

The top-down approach uses the base case $\left(C_{\mathrm{RAI}}\right)$ concentration as reference to compute the concentration impact. In this case, all Stein-Alpert terms are different from the nonlimited regime:

$\Delta C_{\mathrm{R}}^{\mathrm{TD}}=116.6, \quad \hat{C}_{\mathrm{RA}}^{\mathrm{TD}}=-16.6$,

$\Delta C_{\mathrm{A}}^{\mathrm{TD}}=66.6, \quad \hat{C}_{\mathrm{RI}}^{\mathrm{TD}}=33.3$,

$\Delta C_{\mathrm{I}}^{\mathrm{TD}}=116.6, \quad \hat{C}_{\mathrm{AI}}^{\mathrm{TD}}=-16.6$,

$\Delta C_{\mathrm{RAI}}=266.6, \quad \hat{C}_{\mathrm{RAI}}=-33.3$

These results are graphically represented in Fig. 5 (fourth and fifth columns).

\subsubsection{Tagged approach}

The contribution of each source is computed similarly to the non-limited regime. The production of $33.3 \mathrm{~mol}$ of $\mathrm{PM}\left[\mathrm{NH}_{4} \mathrm{NO}_{3}\right]$ and $33.3 \mathrm{~mol}$ of $\mathrm{PM}\left[\left(\mathrm{NH}_{4}\right)_{2} \mathrm{SO}_{4}\right]$ are split among the different sectors using the stoichiometric coeffi-

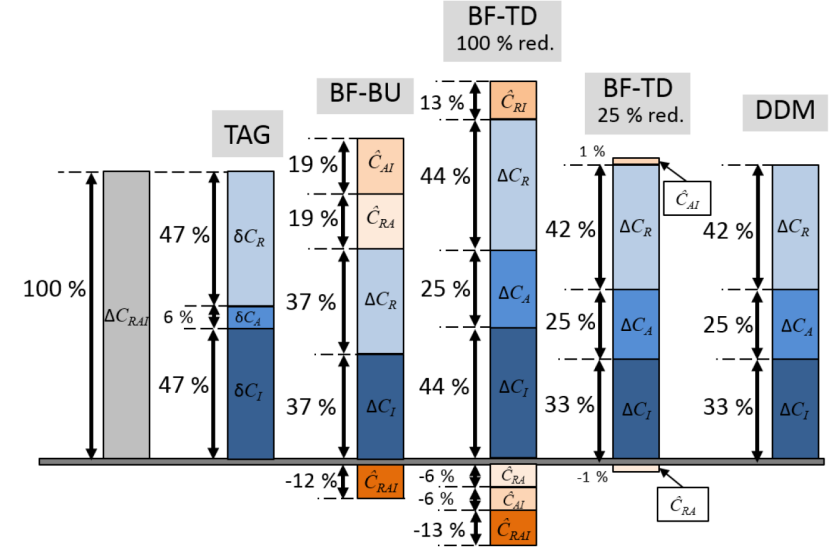

Figure 5. Schematic representation of the allocation of PM to its sources in the ammonia-limited example. The expected total PM is displayed in the grey bar on the left.

cients $a_{1}$ and $a_{2}$ :

$\delta C_{\mathrm{R}}^{\mathrm{TAG}}=100+33.3 \cdot a_{1}=125.8$,
$\delta C_{\mathrm{A}}^{\mathrm{TAG}}=33.3 \cdot\left(1-a_{1}\right)+33.3 \cdot\left(1-a_{2}\right)=16.6$
$\delta C_{\mathrm{I}}^{\mathrm{TAG}}=100+33.3 \cdot a_{2}=124.2$.

These results are graphically represented in Fig. 5 (second column).

\subsubsection{DDM}

As shown below, DDM only considers first derivatives, which are not suitable to estimate higher-order interaction terms. The calculation of the first-order derivatives in this example gives

$$
\begin{aligned}
& \Delta C_{\mathrm{R}}^{\mathrm{HDDM}}=\left.\frac{\partial C}{\partial \alpha_{\mathrm{R}}}\right|_{\mathrm{TD}}=111.5, \\
& \Delta C_{\mathrm{A}}^{\mathrm{HDDM}}=\left.\frac{\partial C}{\partial \alpha_{\mathrm{A}}}\right|_{\mathrm{TD}}=66.7, \\
& \Delta C_{\mathrm{R}}^{\mathrm{HDDM}}=\left.\frac{\partial C}{\partial \alpha_{\mathrm{I}}}\right|_{\mathrm{TD}}=88.1 .
\end{aligned}
$$

These results are graphically represented in Fig. 5 (sixth column).

\subsubsection{Comparative overview}

The main difference with respect to the non-limited regime is the appearance of a triple interaction term that will also lead to differences between the BF-TD and the DDM approaches, given the fact that the latter only accounts for firstorder terms.

In comparison to the non-limited regime, the calculation of the concentration impacts resulting from different percentage of emission reduction shows nonlinear trends (Fig. 6). 


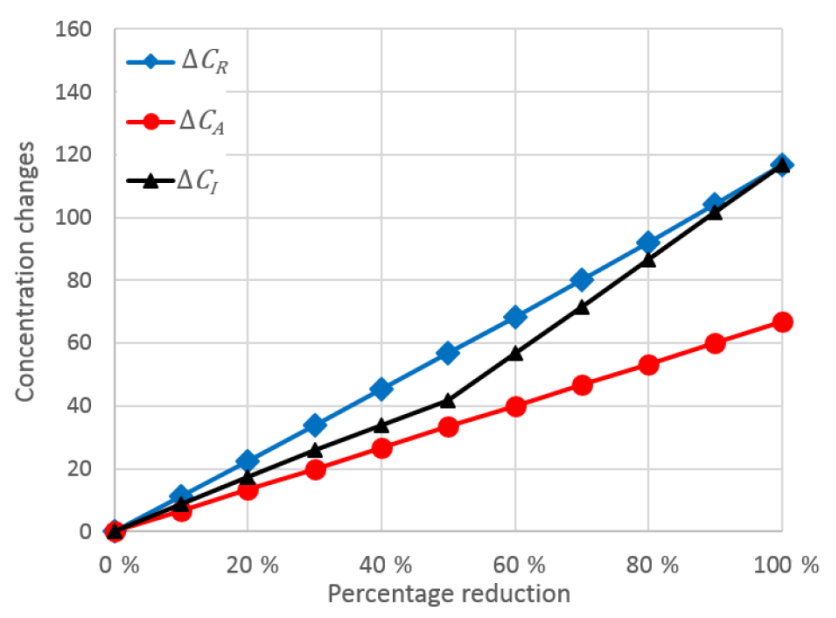

Figure 6. Evolution of the concentration changes resulting from different percentage of source abatement (top-down approach) for the three sectors (residential, agricultural and industrial).

A discontinuity appears at $50 \%$ reduction for the abatement of industrial emissions. This discontinuity corresponds to a change of chemical regime. Below the $50 \%$ reduction level, the quantity of $\mathrm{NH}_{3}$ is not sufficient to feed the reactions with $\mathrm{NO}_{2}$ and $\mathrm{SO}_{2}$ (with no $\mathrm{SO}_{2}$ reduction, $50 \mathrm{~mol}$ of $\mathrm{NO}_{2}$ and $50 \mathrm{~mol}$ of $\mathrm{SO}_{2}$ would require $150 \mathrm{~mol}$ of $\mathrm{NH}_{3}$ but only 100 are available) while beyond this $50 \%$ reduction level the quantity of $\mathrm{NH}_{3}$ is then enough to feed the reactions with $\mathrm{NO}_{2}$ and $\mathrm{SO}_{2}$ (with $50 \% \mathrm{SO}_{2}$ reduction, $50 \mathrm{~mol}$ of $\mathrm{NO}_{2}$ and $25 \mathrm{~mol}$ of $\mathrm{SO}_{2}$ requires $100 \mathrm{~mol}$ of $\mathrm{NH}_{3}$ ).

The methodologies presented in this section aim at decomposing the impact of an ensemble of sources into different terms attributed to each of the individual sources. The terms computed by methodologies designed for source apportionment (like TAG) are named source contributions. Their sum is always equal to the combined impact of all sources. On the other hand, the terms computed by sensitivity analysis represent the emission change of each individual source and their sum is equal to the combined impact of all sources only if the relationship between emissions and concentrations is linear (see Sect. 2). Grewe at al. (2010) and Grewe (2013), who used simple differential equations to reproduce the ozone tropospheric chemistry, also highlighted this point in their work. In nonlinear situations, the source contributions computed for source apportionment and the source impacts computed for sensitivity analysis are different (see Fig. 5, where column 2 shows different results than column 3 or 4). Nonlinearity also implies that the calculation of the source impacts depends on the bounds used to estimate the concentration changes (denoted " $\mathrm{H}$ " and "L" in Sect. 4). The BFBU and BF-TD approaches (columns 3 and 4 in Fig. 5) give different results because they are not using the same reference level ("L" for the BU and " $H$ " for the TD as defined in Sect. 4). Moreover, the results depend from the percentage of emission changes applied to calculate the source impacts as demonstrated by the different source impacts computed with the BF-TD for 100 and $25 \%$ emission reductions (columns 4 and 5 in Fig. 5). We expect that lower percentage emission reductions generate less nonlinearity and lead to a better agreement between the BF-TD and the DDM method (columns 5 and 6 in Fig. 5).

In synthesis, the second example illustrates that all the methodologies tested to find source contributions and source impacts give different results when the relationship emissions-concentrations is nonlinear. A quantification of the potential nonlinearities should therefore be the first step prior to source apportionment or planning applications, to prevent any limitations in their use. When nonlinearity is mild, these limitations may, however, be acceptable in the context of the other uncertainties inherent to complex models.

\section{Conclusions}

In this work, we compared source apportionment and sensitivity approaches and investigated their domain of application. While sensitivity analysis refers to impacts to characterise the concentration change resulting from a given emission change, source apportionment aims to quantify contributions by attributing a fraction of the pollutant concentration to each emission source. In the case of linear (or close to linear) relationships between concentration and emissions, impacts and contributions are equivalent (or close to) concepts. Source apportionment may then be used for air quality planning purposes and, vice versa, sensitivity analysis may be used for quantifying sources contributions.

In many cases, however, linearity is not a valid assumption. In such cases, sensitivity approaches cannot be used to retrieve source apportionment information, unless nonlinear interaction terms are explicitly accounted for. On the other hand, source apportionment approaches (e.g. tagged species approach) intrinsically account for these nonlinear interactions into their source contributions. But because it mixes interaction terms and impacts, which may react in opposite directions, source apportionment should not be used to evaluate the impact of abatement strategies.

Even when using sensitivity analysis for planning, it is important to note that, under nonlinear conditions, the calculated impacts will only provide information for the exact conditions that are considered. Impacts for an emission reduction of $50 \%$ are only valid for exactly that percentage of reduction, and extrapolation to air quality planning with any other emission reduction levels would be inappropriate, unless additional scenarios are tested. Along the same line of reasoning, the importance of the nonlinear interaction terms (among precursors) should be quantified as well when assessing the impact of more sources or precursors. Finally, these nonlinear interaction terms are in most cases not constant with the emission reduction intensities, which imposes 
the further need to quantify them for different levels of emission reduction. Calculating sensitivities and interactions at various level of emission reductions seems the only alternative when nonlinearities are important. In this respect, new approaches like the path-integral methodology proposed by Grewe et al. (2012) might represent a powerful approach.

Fortunately, not all cases are so complex as to require the full quantification of all nonlinear interaction terms. Thunis et al. (2015) showed that for yearly average relationships between emission and concentration changes, linearity is a realistic assumption, implying the possible use of source apportionment and sensitivity analysis for both purposes. Some integrated assessment tools (e.g. GAINS, SHERPA) take advantage of this assumption to retrieve source apportionment information from calculated chemistry transport model sensitivities. Although nonlinearities are important for short-term time averages (e.g. daily means, episodes), they are likely not associated with every process. For instance, nonlinear interactions are expected to be more relevant for secondary pollutants, especially under limited regimes. The challenge consists, therefore, in screening the system for significant nonlinearities and accounting for them by calculating explicitly the relevant nonlinear interaction terms.

One main strength of source apportionment approaches is to provide contribution estimates that can be crossvalidated with source apportionment derived from measurements (i.e. receptor modelling; for a detailed description, see e.g. Belis et al., 2013). This step is crucial for the evaluation of chemistry transport models.

Code availability. No specific code is attached to this work as all presented examples can easily be replicated.

Competing interests. The authors declare that they have no conflict of interest.

Edited by: Gerd A. Folberth

Reviewed by: two anonymous referees

\section{References}

Belis, C. A., Karagulian, F., Larsen, B. R., and Hopke, P. K.: Critical review and meta-analysis of ambient particulate matter source apportionment using receptor models in Europe, Atmos. Environ., 69, 94-108, 2013.

Bhave, P. V., Pouliot, G. A., and Zheng, M.: Diagnostic model evaluation for carbonaceous PM2.5 using organic markers measured in the southeastern U.S., Environ. Sci. Technol., 41, 1577-1583, 2007.

Blanchard, C. L.: Methods for attributing ambient air pollutants to emission sources, Annu. Rev. Ener. Env., 24, 329-365, 1999.

Burr, M. J. and Zhang, Y.: Source-apportionment of fine particulate matter over the Eastern U.S. Part II: source apportionment simulations using CAMx/PSAT and comparisons with CMAQ source sensitivity simulations, Atmos. Pollut. Res., 2, 318-336, 2011 a.
Burr, M. J. and Zhang, Y.: Source-apportionment of fine particulate matter over the Eastern U.S. Part II: source sensitivity simulations using CMAQ with the Brute Force method, Atmos. Pollut. Res., 2, 300-317, 2011b.

Butler, T. M., Lawrence, M. G., Taraborrelli, D., and Lelieveld, J.: Multi-day ozone production potential of volatile organic compounds calculated with a tagging approach, Atmos. Environ., 45 , 4082-4090, 2011.

Clappier, A., Fagerli, H., and Thunis, P.: Screening of the EMEP source receptor relationships: application to five European countries, Air Qual. Atmos. Health, 10, 497-507, 2017.

Crippa, M., Janssens-Maenhout, G., Guizzardi, D., Van Dingenen, R., and Dentener, F.: Sectorial and regional uncertainty analysis of the contribution of anthropogenic emissions to regional and global PM2.5 health impacts, Atmos. Chem. Phys. Discuss., https://doi.org/10.5194/acp-2017-779, in review, 2017.

Dunker, A. M.: The decoupled direct method for calculating sensitivity coefficients in chemical kinetics, J. Chem. Phys., 81, 23852393, 1984.

Dunker, A. M.: Path-integral method for the source apportionment of photochemical pollutants, Geosci. Model Dev., 8, 1763-1773, https://doi.org/10.5194/gmd-8-1763-2015, 2015.

Dunker, A. M., Yarwood, G., Ortmann, J. P., and Wilson, G. M.: The decoupled direct method in a three-dimensional air quality modeldimplementation, accuracy and efficiency, Environ. Sci. Technol., 36, 2965-2976, 2002.

Emmons, L. K., Hess, P. G., Lamarque, J.-F., and Pfister, G. G.: Tagged ozone mechanism for MOZART-4, CAM-chem and other chemical transport models, Geosci. Model Dev., 5, 15311542, https://doi.org/10.5194/gmd-5-1531-2012, 2012.

ENVIRON: User's Guide Comprehensive Air Quality Model with Extensions, Version 6.1, available at: http://www.camx. com/files/camxusersguide_v6-10.pdf (last access: 15 November 2017), 2014

Grewe, V.: Technical Note: A diagnostic for ozone contributions of various $\mathrm{NO}_{x}$ emissions in multi-decadal chemistryclimate model simulations, Atmos. Chem. Phys., 4, 729-736, https://doi.org/10.5194/acp-4-729-2004, 2004.

Grewe, V.: A generalized tagging method, Geosci. Model Dev., 6, 247-253, https://doi.org/10.5194/gmd-6-247-2013, 2013.

Grewe, V., Tsati, E., and Hoor, P.: On the attribution of contributions of atmospheric trace gases to emissions in atmospheric model applications, Geosci. Model Dev., 3, 487-499, https://doi.org/10.5194/gmd-3-487-2010, 2010

Grewe, V., Dahlmann, K., Matthes, S., and Steinbrecht, W.: Attributing ozone to $\mathrm{NO}_{x}$ emissions: Implications for climate mitigation measures, Atmos. Environ., 59, 102-107, 2012.

Grewe, V., Tsati, E., Mertens, M., Frömming, C., and Jöckel, P.: Contribution of emissions to concentrations: the TAGGING 1.0 submodel based on the Modular Earth Submodel System (MESSy 2.52), Geosci. Model Dev., 10, 2615-2633, https://doi.org/10.5194/gmd-10-2615-2017, 2017.

Gromov, S., Jöckel, P., Sander, R., and Brenninkmeijer, C. A. M.: A kinetic chemistry tagging technique and its application to modelling the stable isotopic composition of atmospheric trace gases, Geosci. Model Dev., 3, 337-364, https://doi.org/10.5194/gmd-3337-2010, 2010. 
Hakami, A., Odman, M. T., and Russell, A. G.: High-order, direct sensitivity analysis of multidimensional air quality models, Environ. Sci. Technol., 37, 2442-2452, 2003.

Horowitz, L. and Jacob, D.: Global impact of fossil fuel combustion on atmospheric $\mathrm{NO}_{x}$, J. Geophys. Res., 104, 23823-23840, https://doi.org/10.1029/1999JD900205, 1999.

Kiesewetter, G., Borken-Kleefeld, J., Schöpp, W., Heyes, C., Thunis, P., Bessagnet, B., Terrenoire, E., Fagerli, H., Nyiri, A., and Amann, M.: Modelling street level PM10 concentrations across Europe: source apportionment and possible futures, Atmos. Chem. Phys., 15, 1539-1553, https://doi.org/10.5194/acp15-1539-2015, 2015.

Koo, B., Wilson, G. M., Morris, R. E., Dunker, A. M., and Yarwood, G.: Comparison of Source Apportionment and Sensitivity Analysis in a Particulate Matter Air Quality Model, Environ. Sci. Technol., 43, 6669-6675, 2009.

Kranenburg, R., Segers, A. J., Hendriks, C., and Schaap, M.: Source apportionment using LOTOS-EUROS: module description and evaluation, Geosci. Model Dev., 6, 721-733, https://doi.org/10.5194/gmd-6-721-2013, 2013.

Lelieveld, J. and Dentener, F. J.: What controls tropospheric chemistry, J. Geophys. Res., 105, 3531-3551, 2000.

Meijer, E., van Velthoven, P., Thompson, A., Pfister, L., Schlager, H., Schulte, P., and Kelder, H.: Model calculations of the impact of $\mathrm{NO}_{x}$ from air traffic, lightning, and surface emissions, compared with measurements, J. Geophys. Res., 105, 3833-3850, 2000 .

Seinfeld, J. H. and Pandis, S. N.: Atmospheric Chemistry and Physics: From Air Pollution to Climate Change, ISBN: 978-1118-94740-1, 1152 p., 2016.
Simon, H., Baker, K. R., Akhtar, F., Napelenok, S. L., Possiel, N., Wells, B., and Timin, B.: A direct sensitivity approach to predict hourly ozone resulting from compliance with the National Ambient Air Quality Standard, Environ. Sci. Technol., 47, 2304-2313, 2013.

Stein, U. and Alpert, P.: Factor separation in numerical simulations, J. Atmos. Sci., 50, 2107-2115, 1993.

Thunis, P., Clappier, A., Pisoni, E., and Degraeuwe, B.: Quantification of non-linearities as a function of time averaging in regional air quality modeling applications, Atmos. Environ., 103, 263275, 2015.

Thunis, P., Degraeuwe, B., Pisoni, E., Ferrari, F., and Clappier, A.: On the design and assessment of regional air quality plans: The SHERPA approach, J. Environ. Manag., 183, 952-958, 2016.

Wagstrom, K. M., Pandis, S. N., Yarwood, G., Wilson, G. M., and Morris, R. E.: Development and application of a computationally efficient particulate matter apportionment algorithm in a three dimensional chemical transport model, Atmos. Environ., 42, 56505659, 2008.

Wang, Z. S., Chien, C.-J., and Tonnesen, G. S.: Development of a tagged species source apportionment algorithm to characterize three-dimensional transport and transformation of precursors and secondary pollutants, J. Geophys. Res., 114, D21206, https://doi.org/10.1029/2008JD010846, 2009.

Yarwood, G., Morris, R. E., and Wilson, G. M.: Particulate Matter Source Apportionment Technology (PSAT) in the CAMx Photochemical Grid Model, Proceedings of the 27th NATO/CCMS International Technical Meeting on Air Pollution Modeling and Application, Springer Verlag, Heidelberg, 2004. 